\begin{tabular}{|c|c|c|c|}
\hline \multirow{3}{*}{$\begin{array}{r}\text { Case Reports in } \\
\text { Gastroenterology }\end{array}$} & \multirow{2}{*}{\multicolumn{2}{|c|}{ Case Rep Gastroenterol 2016;10:646-652 }} & \multirow[b]{3}{*}{$\begin{array}{l}\text { Karger } \\
\text { Open'access }\end{array}$} \\
\hline & & & \\
\hline & $\begin{array}{l}\text { DOI: 10.1159/000452210 } \\
\text { Publisned onine. Tvovember 7, } 2016\end{array}$ & $\begin{array}{l}\text { (c) } 2016 \text { The Author(s) } \\
\text { Published by S. Karger AG, Basel } \\
\text { www.karger.com/crg }\end{array}$ & \\
\hline & $\begin{array}{l}\text { This article is licensed under the } \\
\text { International License (CC BY-NC) } \\
\text { Usage and distribution for commercia }\end{array}$ & $\begin{array}{l}\text { nons Attribution-NonCommercial } 4.0 \\
\text { ger.com/Services/OpenAccessLicense). } \\
\text { uires written permission. }\end{array}$ & \\
\hline
\end{tabular}

\title{
Successful Transanal Removal of a Rectal Foreign Body by Abdominal Compression under Endoscopic and X-Ray Fluoroscopic Observation: A Case Report
}

\author{
Hironobu Mikami ${ }^{a} \quad$ Norihisa Ishimura ${ }^{a} \quad$ Akihiko Oka $^{a}$ Ichiro Moriyama ${ }^{b}$

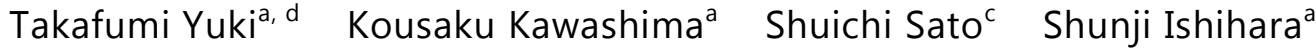 \\ Yoshikazu Kinoshita ${ }^{a}$ \\ ${ }^{a}$ Department of Gastroenterology and Hepatology, Shimane University \\ School of Medicine, Izumo, Japan; ${ }^{b}$ Cancer Center, Shimane University Hospital, \\ Izumo, Japan; 'Division of Gastrointestinal Endoscopy, Shimane University \\ Hospital, Izumo, Japan; 'Division of Gastroenterology, Matsue Red Cross Hospital, \\ Matsue, Japan
}

\section{Keywords}

Rectal foreign body · Compression · Endoscopy · Fluoroscopy

\begin{abstract}
We occasionally encounter patients with various types of rectal foreign bodies. When too large to grasp, transanal removal can be difficult. Here, we report a case of successful manual transanal removal of an $18 \times 4 \times 4 \mathrm{~cm}$ silicon rod without complications. A 50-year-old male came to the emergency department of our hospital $12 \mathrm{~h}$ after transanal insertion of a whole silicon rod. An abdominal examination showed no evidence of peritonitis, while X-ray and computed tomography findings revealed a large foreign body in the rectum, without any sign of perforation. Initially, we attempted removal using an endoscopy procedure with conventional endoscopic instruments, including a snare and grasp forceps, though we failed because of the large size. Next, we manually compressed the foreign body from the abdominal wall under endoscopic and X-ray fluoroscopic observation, and successfully re-
\end{abstract}


moved it in a transanal manner without complications. Endoscopic and X-ray fluoroscopic assistance were helpful to guide the direction and angle of abdominal compression in this case.

\section{Introduction}

Rectal foreign bodies can present a difficult management dilemma, because the types encountered vary widely and they can cause not only local trauma to surrounding tissues but also obstruction or perforation that requires surgical treatment. For effective removal, it is important to precisely determine the size, shape, and material of the foreign body by patient interview and imaging diagnosis, and then to evaluate the possibility of rectal perforation and peritonitis $[1,2]$. In cases without perforation, transanal removal of a rectal foreign body is generally attempted as a first-line procedure in the emergency unit, with a reported success rate of approximately $75 \%$ [3]. However, when the size is too large to grasp, transanal removal is difficult.

We here report a patient with a large rectal foreign body that was successfully removed with manual compression from the abdominal wall, with assistance provided by endoscopic and X-ray fluoroscopic observation.

\section{Case}

A 50-year-old male came to the emergency room of our hospital and stated that a handmade silicon rod had accidentally passed into his rectum $12 \mathrm{~h}$ prior to presentation. He could not remove it on his own. His vital signs were stable, and a physical examination showed that his abdomen was soft and without tenderness. There was a palpable elastic, hard mass in the lower abdomen and no signs of peritonitis. A digital rectal examination by palpation located the end of the foreign body in the deep rectum. An attempt to manually remove it in a transanal manner failed due to its shape, large size, and deep position. Laboratory data were essentially normal, with the exception of slightly elevated C-reactive protein (1.76 $\mathrm{mg} / \mathrm{dL}$ ). Plain abdominal X-ray imaging showed a foreign body in the pelvic area and absence of free air (Fig. 1a), while computed tomography (CT) revealed an $18 \times 4 \mathrm{~cm}$ foreign body with a cylindrical shape in the rectum (Fig. 1b-d). No severe complications, such as perforation or obstruction, were seen. We decided to attempt removal in a transanal manner under endoscopic and X-ray fluoroscopic observation.

Following intravenous administration of $15 \mathrm{mg}$ of pentazocine, a scope (PCF-Q260AZI; Olympus, Japan) was inserted transanally with the patient in a left lateral decubitus position to directly visualize the foreign body. The lateral pelvic view obtained by X-ray fluoroscopy showed the foreign body in the rectosigmoid position. We attempted removal with endoscopic instruments, including a snare, biopsy forceps, grasping forceps, and net, though that failed because of the round shape and large diameter. When manually compressed from the abdominal wall under endoscopic and X-ray fluoroscopic observation, we noticed that the axis of the foreign body changed (Fig. 2). Thus, we were able to guide it using manual abdominal compression with endoscopic and X-ray fluoroscopic assistance. Once the object moved to the lower rectum, it could be removed transanally by manual extraction. After removal, we found that the foreign body was constructed of a silicon material and made by the patient himself, with a size of $18 \times 4 \mathrm{~cm}$ (Fig. 3). Sigmoidoscopy following extraction 
showed mild erosion in the rectal mucosa with no findings of bleeding or perforation. The patient was released without hospitalization or surgery.

\section{Discussion}

Patients with rectal foreign bodies are occasionally encountered in the emergency room. Although not as common as upper gastrointestinal foreign bodies, the incidence has been suggested to be increasing, especially in urban areas [3, 4]. In a review of 196 cases of rectal foreign bodies in 193 patients, it was reported that the mean age at presentation was 44.1 years (range 19-79) with a significantly higher proportion of males (ratio approx. 37:1) [4]. Numerous types of objects have been described in the literature, with the most common being household objects (42.2\%), such as a bottle or glasses, while others include sex toys, personal care, sports equipment, and food [5]. The majority of rectal foreign bodies reported in adults have been purposefully inserted for self-gratification. As they are likely to be smooth, round, cylindrical, or egg shaped for easy insertion [6], it is difficult to grasp and remove them in a transanal manner using standard endoscopic devices.

Because of the wide variety of objects and variation in trauma to local tissues of the rectum and distal colon, a systematic approach to the diagnosis and management of rectal foreign bodies is needed [1,2]. A physical examination and radiological imaging, such as plain X-ray and CT, are important to evaluate the general condition of the patient and to determine a treatment plan [7]. In particular, CT can provide a great deal of information, such as the properties (shape, size) and precise location of the object, as well as the presence of perforation or obstruction. If a clinical or radiological examination shows signs of peritonitis or perforation, surgical procedures such as a laparotomy should immediately be considered [2]. In cases without severe complications, transanal removal is generally attempted in the emergency unit [3]. However, no specific criteria or guidelines have been established regarding an effective strategy for transanal removal of a rectal foreign body. The factors that determine whether a rectal foreign body can be removed transanally are the shape, size, and location of the object $[2,3]$.

To date, various methods for transanal removal of foreign bodies have been reported. Most objects can be safely removed during an endoscopy procedure with the assistance of endoscopic devices such as a snare or forceps [8], while Kocher clamps, suction devices, and various grasping forceps, though designed for other purposes, have been effective $[9,10]$. However, when foreign bodies are too large to be removed by those, other methods, including surgery, are required. In the present case, the object was located in the rectosigmoid area and considered to be removable, though its axial orientation made removal difficult. We attempted that by using various endoscopic instruments, but failed because the object had smooth sides and a large size. Finally, we were able to use abdominal manual compression to guide the proximal end of the object under X-ray fluoroscopic observation and the distal side under endoscopic observation, and successfully removed it transanally without complications.

Endoscopic assistance for removal of a rectal foreign body helps to avoid iatrogenic injury [9]. In addition, gentle air insufflation performed during an endoscopy procedure can make it easier to move the object to the anal side by raising intraluminal pressure on the oral side of the foreign body, which may facilitate transanal removal. Air insufflation is also useful to distend the collapsed distal bowel lumen and allow clear visualization of the foreign body. 
Therefore, endoscopic assistance should be considered as a first step during management for rectal foreign bodies in cases without perforation.

In conclusion, we report the successful transanal removal of a large-sized rectal foreign body. In cases without perforation, a minimally invasive endoscopic technique via a transanal approach should be considered as a first-line procedure. For transanal removal of the present, large-sized object, we found that endoscopic and X-ray fluoroscopic assistance were helpful to guide the direction and angle of abdominal compression.

\section{Statement of Ethics}

The authors have no ethical conflicts to disclose.

\section{Disclosure Statement}

There are no potential conflicts of interest to disclose in association with this study.

\section{References}

1 Goldberg JE, Steele SR: Rectal foreign bodies. Surg Clin North Am 2010;90:173-184.

-2 Koornstra JJ, Weersma RK: Management of rectal foreign bodies: description of a new technique and clinical practice guidelines. World J Gastroenterol 2008;14:4403-4406.

-3 Lake JP, Essani R, Petrone P, Kaiser AM, Asensio J, Beart RW Jr: Management of retained colorectal foreign bodies: predictors of operative intervention. Dis Colon Rectum 2004;47:1694-1698.

4 Kurer MA, Davey C, Khan S, Chintapatla S: Colorectal foreign bodies: a systematic review. Colorectal Dis 2010;12:851-861.

5 Cologne KG, Ault GT: Rectal foreign bodies: what is the current standard? Clin Colon Rectal Surg 2012;25:214-218.

-6 Singaporewalla RM, Tan DE, Tan TK: Use of endoscopic snare to extract a large rectosigmoid foreign body with review of literature. Surg Laparosc Endosc Percutan Tech 2007;17:145-148.

7 Pinto A, Miele V, Pinto F, Mizio VD, Panico MR, Muzj C, Romano L: Rectal foreign bodies: imaging assessment and medicolegal aspects. Semin Ultrasound CT MR 2015;36:88-93.

8 Bak Y, Merriam M, Neff M, Berg DA: Novel approach to rectal foreign body extraction. JSLS 2013;17:342-345.

- Lim KJ, Kim JS, Kim BG, Park SM, Ji JS, Kim BW, Choi H: Removal of rectal foreign bodies using tenaculum forceps under endoscopic assistance. Intest Res 2015;13:355-359.

10 Yılmaz B, Ozmete S, Altınbas A, Aktaş B, Ekiz F: Successful removal of an unusual rectal foreign body with a Kocher clamp. Endoscopy 2014;46(suppl 1 UCTN):E549. 

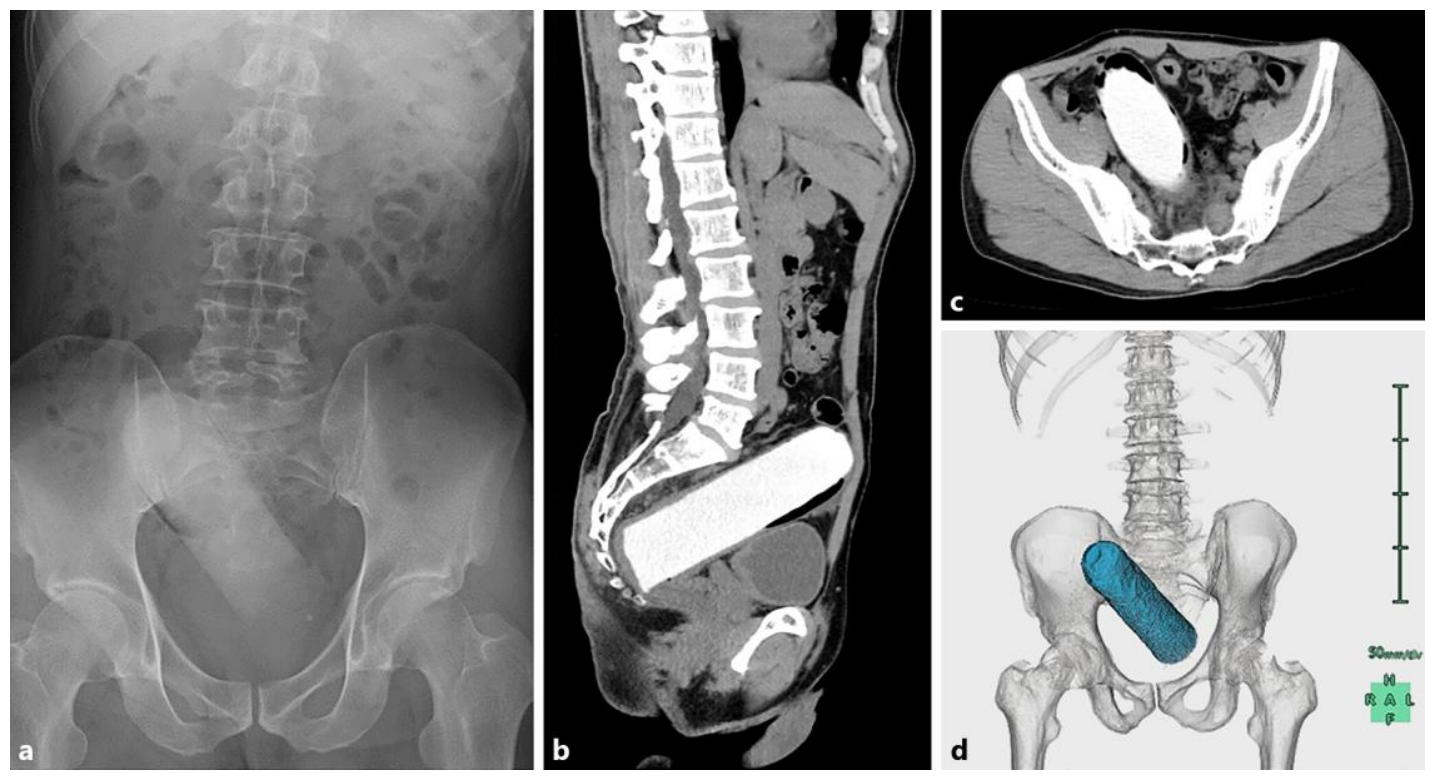

Fig. 1. Abdominal X-ray and CT imaging. a X-ray image showing a foreign body in the pelvic area. b-d Sagittal view (b), axial view (c), and 3-D reconstruction (d) of CT showing the present $18 \times 4 \times 4 \mathrm{~cm}$, cylindrically shaped object in the rectum. The tip of the foreign body was rounded and the proximal side had a columnar construction. 


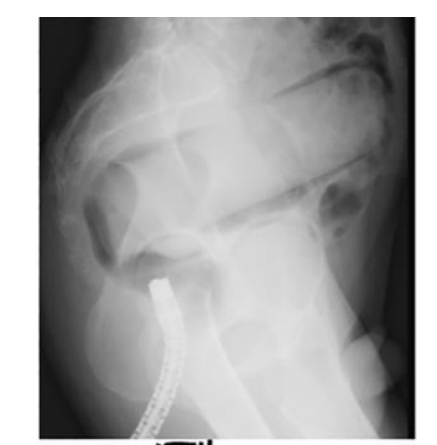

\begin{tabular}{l|l}
\hline DOI: 10.1159/000452210 & $\begin{array}{l}\text { (c) } 2016 \text { The Author(s). Published by S. Karger AG, Basel } \\
\text { www.karger.com/crg }\end{array}$ \\
\hline
\end{tabular}
www.karger.com/crg

Mikami et al:: Successful Transanal Removal of a Rectal Foreign Body by Abdominal Compression under Endoscopic and X-Ray Fluoroscopic Observation: A Case Report
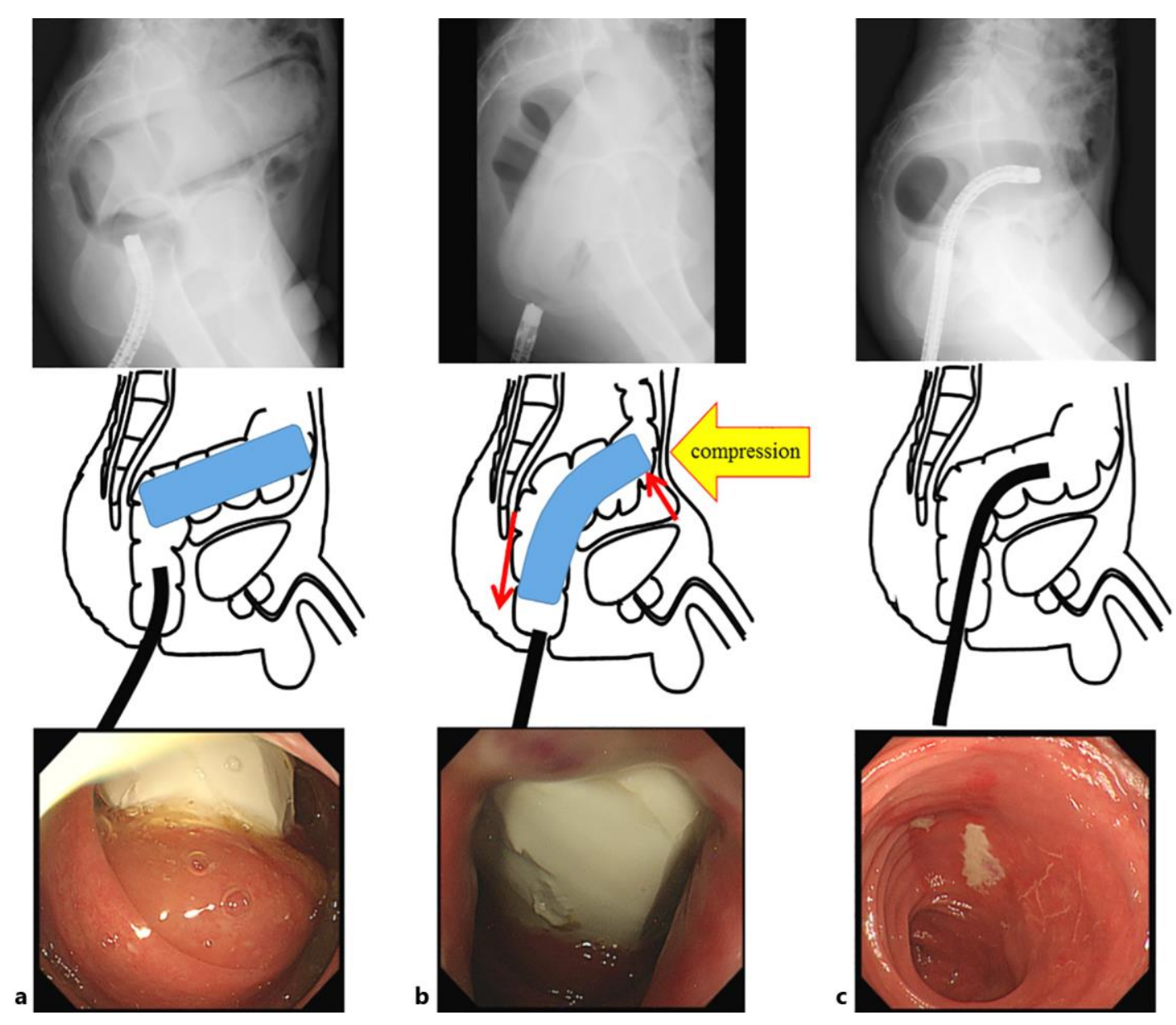

Fig. 2. Transanal manual removal of the foreign body. a X-ray fluoroscopy showing the lateral pelvic view of the foreign body in a rectosigmoid position. $\mathbf{b}$ We changed the axis of the foreign body by manual abdominal compression and moved it to the lower rectum, after which we removed it in a transanal manner by manual extraction. c Sigmoidoscopy following extraction showed mild erosion in the rectal mucosa with no findings of bleeding or perforation. 
Mikami et al.: Successful Transanal Removal of a Rectal Foreign Body by Abdominal Compression under Endoscopic and X-Ray Fluoroscopic Observation: A Case Report

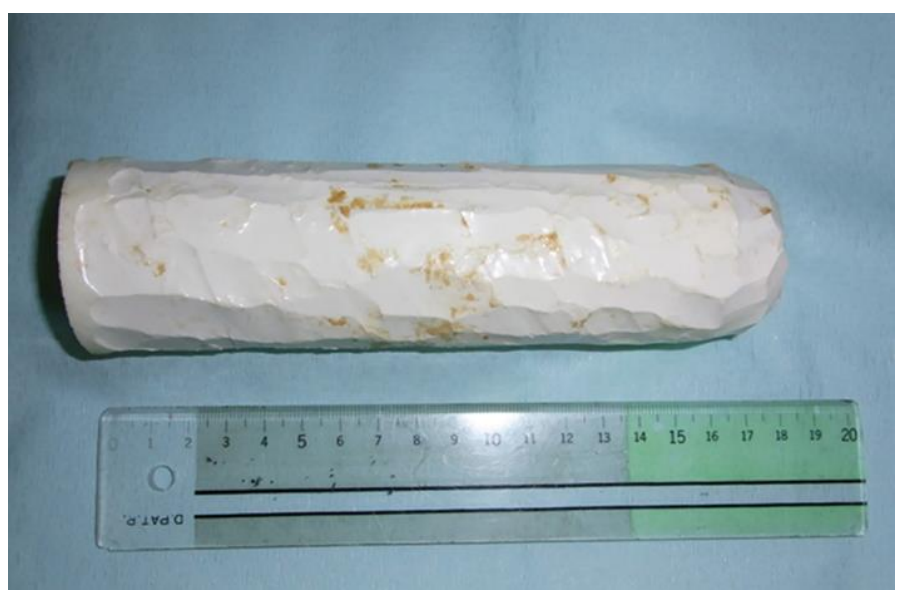

Fig. 3. The foreign body was constructed of silicon material and made by the patient himself $(18 \times 4 \mathrm{~cm})$. 